\title{
A study of relapse in paucibacillary leprosy in a multidrug therapy project, Baroda District, India
}

\author{
N K CHOPRA, J S AGARAWAL \& P G PANDYA \\ Ansuya Leprosy Hospital and Training Centre, Baroda 390 015, \\ Gujarat, India
}

\section{Accepted for publication 2 October 1989}

\begin{abstract}
Summary In order to judge the value of therapeutic regimens in paucibacillary leprosy, knowledge of incubation time of relapses is essential, as this will define the length of time patients have to be followed up after treatment has been stopped. The prospective study of relapse includes paucibacillary cases of leprosy belonging to a non-lepromatous group consisting of tuberculoid, neuritic and indeterminate. Data are presented on the incubation time of 21 relapses after multidrug therapy in Baroda district; $76 \cdot 19 \%$ of relapses occur during the first 2 years. This figure is most important in the analysis of results of drug trials in paucibacillary leprosy. This figure should also be relevant to regimens including drugs that are more bacteriocidal than dapsone, since the bacteriocidal activity has a bearing on the minimal necessary duration of treatment, but not on the incubation time of relapses.

With the introduction of bactericidal drugs e.g. rifampicin in multidrug therapy, the incidence of relapse are very low, hence relapse rates fall down to a very low level after multidrug therapy. Our study shows a mean relapse rate of $0 \cdot 19 \%$ after multidrug therapy. Factors associated with the occurrence of relapse are discussed.
\end{abstract}

\section{Introduction}

There have been only a few studies on relapse in non-lepromatous and intermediate groups of leprosy cases. The non-lepromatous cases form the bulk of the case load of any leprosy control unit. It is recognized that with an effective treatment regimen these types of leprosy regress much more rapidly compared to the lepromatous type of leprosy. However, a certain amount of care has to be exercised while releasing them from control after inactivity to avoid relapses. ${ }^{1,2}$ This study reports risk factors contributing to relapses observed in the multidrug therapy project, Baroda district with the collaboration of the State Government, Government of India and World Health Organization.

\section{Material and methods}

The multidrug therapy project was started on 11 June 1984 and the intensive phase of 3 
years was completed on 10 June 1987; the project has been in its maintenance phase since 11 June 1987. The study of relapse in paucibacillary cases in the MDT project was undertaken from January 1985 to January 1989. The study cases included are paucibacillary cases of leprosy belonging to a non-lepromatous group consisting of tuberculoid (TT), borderline tuberculoid (BT), neuritic (N) and indeterminate (I). The classification followed was that suggested by Ridley \& Jopling. ${ }^{9}$ The criteria followed for diagnosing clinical and bacteriological paucibacillary leprosy cases was as suggested by Job \& Chako. These cases include skin smear negative TT, BT, neuritic and indeterminate. The cases were selected on the criteria prescribed under MDT guidelines which included proper clinical assessment of each case and bacteriological examinations of skin smears of patient. ${ }^{7}$ Amongst 10,348 old active cases, $9770(94 \cdot 41 \%)$ were released from treatment up to January 1989 (3478 MB+6292 PB). New cases detected between commencement of MDT and January 1989 are 9374 (3717 MB + 5657 PB), of which 9291 $(99 \cdot 11 \%)$ were brought under treatment (3697 MB + $5594 \mathrm{~PB})$. Total number of new cases discharged as cured between commencement of MDT and January 1989 are 6823 (2020 $\mathrm{MB}+4803 \mathrm{~PB})$. Thus a total of 11,095 paucibacillary cases were released from control up to January 1989, of which, only 21 cases relapsed. All of the relapsed cases were diagnosed clinically, bacteriologically and confirmed by histopathology.

These cases of relapse were differentiated clinically from reversal reaction by slow and insidious onset, time interval of 6 months after stopping treatment, new lesions were minimal, lesion showed erythema and infiltration, ulceration does not occur and very slow response to treatment.

\section{TREATMENT}

Paucibacillary cases were given dapsone $100 \mathrm{mg}$ daily for 6 months and supervised rifampicin $600 \mathrm{mg}$ once a month for 6 months. ${ }^{12} 723$ PB cases were clinically active, erythema and infiltration were still persisting. Therefore a further extension of treatment for 6 months were given to 723 cases. All PB cases released from treatment were followed once in 6 months for 2 years.

\section{Results/Observations \\ (Non-lepromatous and paucibacillary used synonymously; $R \mathbf{R}=$ Relapse rate)}

The observations are given in the tables.

\section{RELAPSE RATE: (Table 1)}

It will be observed from Table 1, which gives the number of relapse cases over the years, that the relapse rate has been rising which is natural as the number of cases discharged have been increasing cumulatively. The average relapse rate is $0 \cdot 19 \%$. All 21 relapsed cases were on multidrug therapy and all cases were also bacteriologically positive.

Table 1 shows the number of cases that relapsed yearly out of the total number of PB cases released from treatment. The first case relapsed in the year 1984-85 out of $1210 \mathrm{~PB}$ cases released from treatment. Thus 21 cases relapsed out of the 10,995 PB cases released from treatment with a mean relapse rate of $0 \cdot 19 \%$. Relapses in leprosy are less common 
Table 1. Relapse cases yearwise from total number of PB cases released from treatment

\begin{tabular}{cccc}
\hline Year & $\begin{array}{c}\text { Total PB cases } \\
\text { RFT }\end{array}$ & $\begin{array}{c}\text { No. of cases } \\
\text { relapsed yearwise }\end{array}$ & $\begin{array}{c}\text { Relapse rate } \\
(\%)\end{array}$ \\
\hline $1984-85$ & 1210 & 1 & $0 \cdot 08$ \\
$1985-86$ & 2644 & 4 & $0 \cdot 18$ \\
$1986-87$ & 4404 & 6 & $0 \cdot 13$ \\
$1987-88$ & 1717 & 6 & $0 \cdot 34$ \\
$1988-89$ & 1020 & 4 & $0 \cdot 23$ \\
$($ Jan.) & & & $0 \cdot 19$ \\
\hline Total & 10,995 & 21 & \\
\hline
\end{tabular}

after giving multidrug therapy compared to relapses after dapsone monotherapy. Our study shows a very low $0 \cdot 19 \%$ relapse rate after multidrug therapy.

\section{AGE AND SEX IN RELAPSE CASES: (Table 2)}

The proportion of males to females is more in relapse cases. In fact, the usual male preponderance in the disease prevalence is exaggerated in the relapse cases. Amongst both males and females the higher age groups faced more relapse, especially in the 20-30 and over 40 age groups. Out of 21 relapsed cases only 6 cases were irregular in treatment $(28 \cdot 5 \%)$ as shown in Table 2.

\section{CHANGE IN TYPE: (Table 3)}

In connection with classification of leprosy in the field it was noticed that patients had been classified as tuberculoid even when there were multiple lesions. Many of these cases would be classified as borderline tuberculoid at the present time. If the modern concept of classification had been applied perhaps cases would not have been released without a longer maintenance treatment. It will be observed that only $4(23.80 \%)$ out of $17 \mathrm{~PB}$ originally termed $T$ have been relapsed to $T$ but the remaining 13 have relapsed by changing their types. It can be seen from Table 3 on the number of patches that there were

Table 2. Distribution, age, sex for relapsed cases with treatment regularity

\begin{tabular}{ccccccr}
\hline & \multicolumn{2}{c}{ Sex groups } & & \multicolumn{2}{c}{ Treatment } \\
\cline { 2 - 3 } $\begin{array}{c}\text { Age groups } \\
\text { (Years) }\end{array}$ & Male & Female & & Regular & Irregular & Total \\
\hline $0-14$ & 1 & - & & 1 & - & 1 \\
$15-25$ & 1 & 1 & & 1 & 1 & 2 \\
$26-40$ & 5 & 2 & & 5 & 2 & 7 \\
Over 40 & 9 & 2 & & 8 & 3 & 11 \\
\hline Total & 16 & 5 & & 15 & 6 & 21 \\
\hline
\end{tabular}


Table 3. Changes in types due to relapse

\begin{tabular}{lcccccccc}
\hline & \multicolumn{7}{c}{ On relapse } \\
\cline { 2 - 8 } $\begin{array}{c}\text { On } \\
\text { admission }\end{array}$ & TT & I & P & BT & BB & BL & LL & Total \\
\hline TT & 4 & 1 & 1 & 9 & 1 & 1 & - & 17 \\
P. Sec. & - & - & - & 1 & - & - & - & 1 \\
P & 1 & - & - & - & - & - & 1 & 2 \\
I & - & - & - & - & 1 & - & - & 1 \\
\hline Total & 5 & 1 & 1 & 10 & 2 & 1 & 1 & 21 \\
\hline
\end{tabular}

cases without skin lesions who were either primary polyneuritic or secondary polyneuritic or had infiltration. It will be observed that these cases have been transformed into more serious forms.

In our study of relapse 2 cases were pure neuritic type without any evidence of a history of skin lesions whereas one case was of secondary polyneuritic in which multiple nerves were thickened and tender with a past history of skin lesions.

\section{DEFORMITY STATUS AND RELAPSE: (Table 4)}

Out of 21 relapsed cases, 17 cases had no deformities and 4 cases developed deformity on relapse, out of which two had grade 2 , one had grade 1 and one had grade 3 deformity. 15 cases were regular in treatment and the remaining 6 cases were irregular out of which two developed grade 2 deformity and one developed grade 3 deformity.

The above table shows time of relapses (release interval) in PB cases after MDT. The

Table 4. Number of cases that developed deformity amongst relapsed cases under MDT project

\begin{tabular}{ccccc}
\hline & \multicolumn{4}{c}{$\begin{array}{c}\text { Number of cases that } \\
\text { Teveloped deformity grading }\end{array}$} \\
\cline { 2 - 5 } $\begin{array}{c}\text { Total } \\
\text { number of }\end{array}$ & G1 & G2 & G3 & Total \\
\hline 21 & 1 & 2 & 1 & 4 \\
\hline
\end{tabular}

Table 5. Time of relapse (relapse interval)

\begin{tabular}{cccc}
\hline & \multicolumn{3}{c}{ No. of patients } \\
\cline { 2 - 4 } & $1 \mathrm{Yr}$ & $1-2 \mathrm{Yr}$ & $2-3 \mathrm{Yr}$ \\
\hline TT & 1 & 4 & 1 \\
BT & - & 10 & 3 \\
P & - & 1 & 1 \\
\hline
\end{tabular}


majority of relapsed cases in our study after treatment manifest themselves within a period of 3 years. Out of 21 relapses 16 relapses $(76.19 \%)$ manifested within 2 years of the completion of multidrug therapy and the remaining 5 cases $(23.80 \%)$ relapsed in the $3 \mathrm{rd}$ year.

\section{Discussion}

In the early days of sulphone therapy Lowe had observed $11.6 \%$ of relapse which had occurred in 6-12 months after stopping treatment. ${ }^{6}$ Davey ${ }^{3}$ had reported a relapse rate of $6 \%$ in tuberculoid cases, among indeterminate and borderline cases the relapse rate was $29 \%$. Ekambaram ${ }^{4}$ had reported a relapse rate of $1.8 \%$ in patients treated for 5-6 years with $56 \%$ occurring within the first 2 years and $73.5 \%$ within the first 3 years. Ramu \& Ramanujam ${ }^{8}$ found a relapse rate of $4.4 \%$ in borderline cases treated for 3-9 years after subsidence and no relapses were seen after the 5 th year. Girdhar et al. ${ }^{5}$ found a relapse rate of $2.5 \%$ in patients treated according to conventional methods of induction, relapses in leprosy are common after dapsone monotherapy. Repeated relapses in single cases have not been documented though there may be a few such instances. Vellut ${ }^{11}$ found that longer maintenance follow-up led to a lower risk of relapse. Relapses after giving multidrugs are expected to be less common compared to relapses after dapsone monotherapy. The present study proves relapses are less common in multidrug therapy, in comparison to the above studies on dapsone monotherapy; out of 21 relapses 16 manifested in the first 2 years $(76 \cdot 19 \%)$ and the remaining 5 cases $(23.80 \%)$ relapsed in the 3rd year. Touw-Langendijk \& $\mathrm{Naafs}^{10}$ observed a $14 \%$ relapse among T.T. patients treated for 1.5 years and $28 \%$ for patients treated less than 5 years.

Differences in these studies may be the result of differences in the follow-up period or different diagnostic criteria between clinicians. In our study each relapse case was documented by histopathology. It may be that some relapses appearing early after stopping treatment, for instance during the first year, may in reality be upgrading reaction. Where onset is sudden, new lesions are maximum and these lesions may ulcerate, multiple nerve involvement with pain and tenderness and respond to antireactional treatment rapidly. It is frequently argued that the nature of drugs, for example RFM instead of dapsone, will profoundly influence the incubation time for relapses. This results from confusion of two different issues: the incidence of relapses and the moment at which they appear. Indeed, nature and duration of therapy must influence the incidence of relapses, since these are the result of insufficient killing of aetiologic bacilli. However, the moment at which the survivors start to multiply again in most patients must be independent of the kind of anti-bacterial treatment administered. Survivors are survivors, whether the dead ones were killed by dapsone or rifampicin or any other drug.

Relapse is the result of bacterial multiplication starting anew from the survivors remaining after insufficient chemotherapy, due to an insufficiently bacteriocidal drug or to a therapeutic regimen that was too short. It should be mentioned that shortcomings of bacteriocidal activity of drugs is frequently corrected by prolonging the duration of chemotherapy.

In conclusion relapses in leprosy are common after dapsone monotherapy. Relapses after giving multidrugs are expected to be less common compared to relapses after dapsone monotherapy. Our study shows a very low $0 \cdot 19 \%$ relapse rate after multidrug 
therapy. The majority of relapsed cases in our study after treatment manifest themselves within a period of 3 years. Out of 21 relapses, 16 relapses $(76 \cdot 19 \%)$ manifested within the first 2 years of completion of multidrug therapy and the remaining 5 cases $(23 \cdot 80 \%)$ relapsed in the 3 rd year. With the introduction of bacteriocidal drugs, e.g. rifampicin, in multidrug therapy, the incidence of relapse are very low, hence relapse rates fall down to a very low level after multidrug therapy. Our study shows a mean relapse rate of $0 \cdot 19 \%$ after multidrug therapy.

\section{Acknowledgments}

We are very thankful to the World Health Organization and the Swedish International Development Agency (SIDA) - without their financial support this study could not have been undertaken. Our special thanks to Dr C K Rao, Deputy Director General of Leprosy, New Delhi and Director of Health \& Medical Services, Gandhinagar for expert guidance and constant encouragement while undertaking this study. I am also very grateful to the Indian leprosy Association, New Delhi for sponsoring me at the 13th International Leprosy Congress held at The Hague, The Netherlands from 11-17 September 1988, where this paper was presented.

\section{References}

1 Annual Report of CLT \& RI (1977). Relapses in non-lepromatous leprosy under DDS therapy relationship to treatment status after inactivation, p 34-6.

2 Browne SG. Relapses in leprosy. Int J Lep, 1965; 33: 273-8.

3 Davey TF. Discussion transactions of the VII International Congress of Leprology. Tofu Kiyokai Japanese leprosy Foundation, 1959, p 241.

4 Ekambaram V. Duration of treatment for disease arrest of non lepromatous cases and relapse rate in these patients. Lepr Rev, 1979; 50: 297-302.

5 Girdhar BK, Ramu G, Desikan KV. Short course treatment of tuberculoid patients-A feasibility study. Lepr India, 1983; (to be published).

${ }^{6}$ Lowe J. The late results of sulphone treatment of leprosy in East Nigeria. Lepr Rev, 1954; 25: 113-24.

7 Operational guide and guidelines of assessment of leprosy control work in India. New Delhi: Directorate General of Health Services, 1964, p 100.

${ }^{8}$ Ramu G, Ramanujam K. in leprosy. Lepr India, 1974; 46: 1-7.

9 Ridley DS, Jopling WH. A classification of leprosy according to variety of five group system. Int J Le pr, 1966; 34: $225-61$.

10 Touw-Langendijk EMJ, Naafs, B. Relapses in leprosy after release from control. Lepr Rev, 1979; 50: $123-7$.

11 Vellut C, Lechat MF, Misson CB. Maintenance therapy in non-lepromatous leprosy. Int J Le pr, 1979; 47: $432-3$.

12 WHO Study Group. Chemotherapy of leprosy for control programmes. Technical Report Series No. 675. WHO: Geneva, 1982.

13 Waters et al. Lepr Rev, 1986; 57 (Supplement 3), 92. 